\title{
Mechanism underlying long non-coding RNA ILF3-AS1-mediated inhibition of cervical cancer cell proliferation, invasion and migration, and promotion of apoptosis
}

\author{
LINMEI ZHU ${ }^{1 *}$, RUIXIA CHEN ${ }^{2 *}$, CHUNLIN JIANG $^{1}$, QINGSHENG XIE $^{3}$, \\ WENSHUAI ZHAO ${ }^{2}, \mathrm{XIAOHONG} \mathrm{GAO}^{1}$ and HAIMING HUANG ${ }^{2}$ \\ ${ }^{1}$ Department of Obstetrics and Gynecology, Guangdong Clifford Hospital, Guangzhou, \\ Guangdong 511495; Departments of ${ }^{2}$ Anesthesiology and ${ }^{3}$ Gynecology, Sun Yat-sen Memorial Hospital, \\ Sun Yat-sen University, Guangzhou, Guangdong 510120, P.R. China
}

Received February 14, 2020; Accepted November 24, 2020

DOI: $10.3892 / \mathrm{mmr} .2021 .12193$

\begin{abstract}
Long non-coding RNA ILF3 divergent transcript (ILF3-AS1) displays a tumor-suppressing effect. StarBase predicted that the potential target microRNA (miR) of ILF3-AS1 was miR-454-3p; therefore, the present study investigated the effect of ILF3-AS1 and its target miR-454-3p on cervical cancer (CC). Gene Expression Profiling Interactive Analysis was used to predict the expression of ILF3-AS1 in $\mathrm{CC}$ and the overall survival rate of patients. The present study demonstrated that ILF3-AS1 expression was significantly downregulated in human CC tissues and cells compared with adjacent tissues (ANTs) and normal cervical epithelial cells (NCEs), respectively. Patients with CC with high ILF3-AS1 expression displayed higher survival rates compared with patients with low ILF3-AS1 expression. Cell viability, apoptosis, migration and invasion were detected by performing Cell Counting Kit-8, flow cytometry, wound healing and Transwell assays, respectively. Compared with the negative control (NC) group, ILF3-AS1 overexpression significantly inhibited CC cell viability and migration, but significantly increased CC cell apoptosis. Moreover, ILF3-AS1 overexpression significantly upregulated E-Cadherin expression levels, but significantly downregulated $\mathrm{N}$-Cadherin and snail family
\end{abstract}

Correspondence to: Dr Haiming Huang, Department of Anesthesiology, Sun Yat-sen Memorial Hospital, Sun Yat-sen University, 107 West Yanjiang Road, Yuexiu, Guangzhou, Guangdong 510120, P.R. China

E-mail: heminghw@163.com

*Contributed equally

Abbreviations: CC, cervical cancer; lncRNA, long non-coding RNA; RT-qPCR, reverse transcription-quantitative PCR; CCK-8, Cell Counting Kit- 8

Key words: cervical cancer, lncRNA ILF3 divergent transcript, microRNA-454-3p, PTEN transcriptional repressor 1 expression levels compared with the NC group. miR-454-3p expression was negatively correlated with ILF3-AS1, and highly expressed in CC tissues and cells compared with ANTs and NCEs, respectively. PTEN, which was predicted and verified as the target gene for miR-454-3p, was significantly downregulated in CC tissues and cells compared with ANTs and NCEs, respectively. ILF3-AS1 expression was positively correlated with PTEN expression, and ILF3-AS1 overexpression partially reversed the inhibitory effect of miR-454-3p on PTEN expression. In conclusion, the present study indicated that ILF3-AS1 inhibited CC cell proliferation and migration, and promoted CC cell apoptosis by inhibiting epithelial-mesenchymal transition, and ILF3-AS1 overexpression partially reversed the inhibitory effect of miR-454-3p on PTEN expression.

\section{Introduction}

Cervical cancer (CC) is the second most common malignant tumor among women in Latin America $(1,2)$. The mortality of CC in developing countries is $\sim 80 \%$, with $\sim 106,000$ new cases and 48,000 deaths in China in 2018 (3). A large number of studies have demonstrated that $\mathrm{CC}$ is induced by several factors, including bacterial infections, sexual disorders, multiple pregnancies and long-term oral contraceptives (4-6). Harald zur Hausen demonstrated for the first time that human papilloma virus (HPV) infection is a key cause of CC $(7,8)$. Although the development and application of HPV vaccines has increased in popularity, the occurrence and development of tumors is a complex regulation process involving multiple genes (9); therefore, activation of proto-oncogenes and inactivation of tumor suppressor genes may serve as a promising therapeutic strategy in CC.

Long non-coding RNAs (lncRNAs) are a type of RNA that lack protein-encoding functions, and are widely involved in cell proliferation, differentiation and apoptosis (10). IncRNAs are $>200$ nucleotides in length (11) and the majority of non-protein coding sequences are transcribed into lncRNAs (12). lncRNAs are tissue- and cell-specific, and can regulate the growth and development of single-cell eukaryotes, embryonic stem cells 
and adult stem cells (13). Abnormal expression or functions of lncRNAs are closely related to the occurrence and development of cancer (14-16). An integrated analysis of IncRNA-associated networks in CC indicated that several lncRNAs might serve as novel molecular markers for the diagnosis and prognosis of CC (17). Increasing evidence demonstrates that lncRNAs, such as XLOC_006390 (18), small nucleolar RNA host gene 1 (19), are important regulators of $\mathrm{CC}$ progression. However, the functions of lncRNAs in CC are not completely understood.

ILF3 divergent transcript (ILF3-AS1) is an IncRNA located on chromosome 19p 13.2 (20). IncRNA ILF3-AS1 is highly expressed in melanoma cells, promoting cell proliferation, migration and invasion via negative regulation of microRNA (miR/miRNA)-200b/a/429, which suggests that ILF3-AS1 may serve as a potential prognostic biomarker and therapeutic target for melanoma $(20,21)$. In addition, ILF3-AS1 expression is significantly upregulated in osteosarcoma tissues and cells, which promotes osteosarcoma development by regulating the miR-212/SOX5 axis (22). Moreover, ILF3-AS1 is a potential biomarker for colon (23) and prostate (24) cancer. Similarly, previous studies reported that ILF3-AS1 might serve as a prognostic biomarker for CC $(25,26)$. However, the specific regulatory mechanism underlying ILF3-AS1 in CC is not completely understood, thus, the present study investigated the effects and mechanisms underlying ILF3-AS1 in CC.

\section{Materials and methods}

Ethics statement. All patients provided written informed consent. The study was approved by the Ethics committee of Guangdong Clifford Hospital (approval no. 2014007XHK).

CC specimen collection and survival analysis. CC tissues (15 stage I/II cases and 17 stage III/IV cases) and adjacent tissues (ANTs; distance from tumor margin, $2 \mathrm{~cm}$; $\mathrm{n}=32$ ) were collected during CC (age, 37-55 years; female patients) resection at Guangdong Clifford Hospital (Guangzhou, China) between January 2017 and December 2018. Patients with CC were categorized into stages I-IV according to the criteria of the International Society of Oncology and the International Association of Obstetricians and Gynecologists (27). The exclusion criteria were as follows: i) Combined with other malignancies; ii) receiving radiotherapy and chemotherapy for $\mathrm{CC}$; and iii) and acute inflammation of the reproductive tract. Patients diagnosed with cervical cancer via pathological examination were included in the present study. Tissues were washed with sterile saline, snap-frozen in liquid nitrogen for $15 \mathrm{~min}$ and stored at $-80^{\circ} \mathrm{C}$.

Database analysis. The expression and pathological stage plots of ILF3-AS1 in cervical and endocervical cancer were obtained from the Gene Expression Profiling Interactive Analysis (GEPIA) database (gepia.cancer-pku.cn). Kaplan-Meier analysis was performed to assess the survival of patients with CC based on data obtained from the GEPIA database. Survival curves were compared using log-rank tests.

Cell culture. Normal cervical epithelial cell line (NCE; PCS-480-011) and CC cell lines, including C33A (HTB-31), ME-180 (HTB-33), SiHa (HTB-35), HeLa (CCL-2) and
CaSki (CRM-CRL-1550), were purchased from American Type Culture Collection. Cells were cultured in DMEM (cat. no. 12800017; Gibco; Thermo Fisher Scientific, Inc.) supplemented with 10\% FBS (cat. no. 10437085; Gibco; Thermo Fisher Scientific, Inc.) at $37^{\circ} \mathrm{C}$ with $5 \% \mathrm{CO}_{2}$.

Transfection. The overexpression vector pcDNA 3.1 (cat. no. V86020; Invitrogen; Thermo Fisher Scientific, Inc.) containing ILF3-AS1 was constructed. SiHa and HeLa cells were transfected with $2 \mu \mathrm{g}$ ILF3-AS1, miR-454-3p mimic, ILF3-AS1 + miR-454-3p mimic or the corresponding controls [empty vector pcDNA 3.1 plasmid and mimic control (scrambled), 5'-UAGGUCUAA AUGUCUAUUGAUGG-3'] using Lipofectamine ${ }^{\circledR} 3000$ (cat. no. L3000015; Thermo Fisher Scientific, Inc.). Briefly, $1 \mu \mathrm{g}$ ILF3-AS1 overexpression vector or 30 pmol miR-454-3p mimic (cat. no. 4464066; Thermo Fisher Scientific, Inc.; 5'-UAGUGCAAUAUUGCUUAUAGG GU-3') was added to Opti-MEM ${ }^{\circledR}$ medium (cat. no. 31985062; Invitrogen; Thermo Fisher Scientific, Inc.). Subsequently, $3 \mu \mathrm{l}$ Lipofectamine 3000 reagent was added to Opti-MEM medium. Following gentle mixing of the two mixtures at room temperature, $\mathrm{CC}$ cells $\left(5 \times 10^{5}\right.$ cells/well) were incubated with the combined mixture. Blank cells were treated with transfection reagent alone. Cells in the negative control (NC) group were transfected with empty pcDNA 3.1 plasmid. Cells in the control group were co-transfected with empty pcDNA 3.1 plasmid and mimic control. The following mimic control was used: 5'-UAGCAAGgagGUCUAUGUUAUUU-3'. Transfection was performed at room temperature for $15 \mathrm{~min}$. At $48 \mathrm{~h}$ post-transfection, subsequent experiments were performed.

Target gene prediction. The target miRNA of ILF3-AS1 was predicted using StarBase (starbase.sysu.edu.cn) (28). TargetScan (version 7.2; www.targetscan.org) was used to analyze miRNA-mRNA interactions (29).

Luciferase assay. The dual-luciferase reporter assay was performed to verify predictions. The following four reporter plasmids were constructed using the pmirGLO plasmid (cat. no. CL414-01; Beijing Biomed Gene Technology Co., Ltd.): i) Wild-type (WT) ILF3-AS1 (ILF3-AS1-WT); ii) mutant (MUT) ILF3-AS1 (ILF3-AS1-MUT); iii) WT PTEN (PTEN-WT); and iv) mutant PTEN (PTEN-MUT). The four reporter plasmids had the following sequences: i) ILF3-AS1-WT, 5'-AGCCGAGAUUGCUCCAUUGCA CUC-3'; ii) ILF3-AS1-MUT, 5'-AGGGGUGUUUCG UCCUAACGUGAC-3'; iii) PTEN-WT, 5'-CAUUAUAAU GGGCUUUUGCACUG-3'; and iv) PTEN-MUT, 5'-CAU CGAUGUGGGCUUCCUUGACG-3'. Cells were seeded $\left(5 \times 10^{5}\right.$ cells/well) into 24 -well plates and cultured overnight. Subsequently, SiHa and HeLa cells were co-transfected with 50 ng ILF3-AS1-WT, ILF3-AS1-MUT, PTEN-WT or PTEN-MUT reporter plasmid and 100 pmol miR-454-3p mimic or mimic control using Lipofectamine ${ }^{\circledR} 3000$ reagent (Invitrogen; Thermo Fisher Scientific, Inc.) according to the manufacturer's instructions for $48 \mathrm{~h}$ at $37^{\circ} \mathrm{C}$. At $48 \mathrm{~h}$ post-transfection, firefly and Renilla luciferase activities were detected using the Dual-luciferase Reporter Assay System (cat. no. E1910; Promega Corporation). Firefly luciferase activities were normalized to Renilla luciferase activities. 
Reverse transcription-quantitative PCR (RT-qPCR). Total RNA was extracted from tissues and cells using TRIzol ${ }^{\circledR}$ reagent (cat. no. 15596026; Invitrogen; Thermo Fisher Scientific, Inc.). Total RNA concentrations were detected using a NanoDrop 2000 spectrophotometer (Thermo Fisher Scientific, Inc.). Total RNAs were reverse transcribed into cDNA using the Revert Aid First Strand cDNA Synthesis Kit (cat. no. k1622; Thermo Fisher Scientific, Inc.). For detection of miR-454-3p expression, reverse transcription was performed using the All-in-One ${ }^{\mathrm{TM}}$ miRNA First-Reverse Transcription, Strand cDNA Synthesis Kit (cat. no. QP056; GeneCopoeia, Inc.). Both RT kits were used according to the manufacturer's protocol. Subsequently, qPCR was performed using a Veriti ${ }^{\mathrm{TM}}$ 96-Well Fast Thermal Cycler (cat. no. 4375305; Thermo Fisher Scientific, Inc.) and PowerUp ${ }^{\mathrm{TM}}$ SYBR $^{\mathrm{TM}}$ Green Master Mix (cat. no. A25742; Applied Biosystems; Thermo Fisher Scientific, Inc.). The following thermocycling conditions were used for qPCR: Initial denaturation at $95^{\circ} \mathrm{C}$ for $10 \mathrm{~min}$; 40 cycles of denaturation at $95^{\circ} \mathrm{C}$ for $15 \mathrm{sec}$, annealing at $60^{\circ} \mathrm{C}$ for $1 \mathrm{~min}$ and elongation at $95^{\circ} \mathrm{C}$ for $10 \mathrm{sec}$; and extension at $65^{\circ} \mathrm{C}$ for $60 \mathrm{sec}$. The following primers were used for qPCR: IncRNA ILF3-AS1 forward, 5'-TAAACCCCACTG TCTTCC-3' and reverse, 5'-TTCCTTGCTCTTCTTGCTC-3'; PTEN forward, 5'-TTTGAAGACCATAACCCACCAC-3' and reverse, 5'-ATTACACCAGTTCGTCCCTTTC-3'; GAPDH forward, 5'-AATGGACAACTGGTCGTGGAC-3' and reverse, 5'-CCCTCCAGGGGATCTGTTTG-3'; miR-454-3p forward, 5'-GGGTGTCGTATCCAGTGCAA-3' and reverse, 5'-GTC GTATCCAGTGCGTGTCG-3'; and U6 forward, 5'-AGTAAG CCCTTGCTGTCAGTG-3' and reverse, 5'-CCTGGGTCT GATAATGCTGGG-3'. miRNA and mRNA expression levels were quantified using the $2^{-\Delta \Delta C q}$ method (30) and normalized to the internal reference genes U6 and GAPDH, respectively.

Cell Counting Kit-8 (CCK-8) assay. SiHa and HeLa cell viability was assessed by performing CCK- 8 assays. Cells were seeded $\left(5 \times 10^{3}\right.$ cells $\left./ \mathrm{ml} ; 100 \mu \mathrm{l}\right)$ into 96 -well plates, with six replicate wells for each experimental group. Following incubation for 24,48 and $72 \mathrm{~h}$ at $37^{\circ} \mathrm{C}, 10 \mu \mathrm{l}$ CCK-8 reagent (cat. no. PA584814; Thermo Fisher Scientific, Inc.) was added to each well and incubated for $4 \mathrm{~h}$. The absorbance was measured at a wavelength of $450 \mathrm{~nm}$ using an iMARK microplate absorbance reader (Bio-Rad Laboratories, Inc.).

Colony formation assay. SiHa and HeLa cells were seeded $\left(1 \times 10^{2}\right.$ cells/well) into 6-well plates and incubated at $37^{\circ} \mathrm{C}$ with $5 \% \mathrm{CO}_{2}$. After 2 weeks, cells were thoroughly washed with PBS, fixed with $5 \mathrm{ml}$ 100\% methanol (cat. no. M116119-4L; Shanghai Aladdin Biochemical Technology Co., Ltd.) for $15 \mathrm{~min}$ at room temperature and stained with Giemsa stain (cat. no. 32884-250ML; Sigma-Aldrich; Merck KGaA) for $20 \mathrm{~min}$ at room temperature. Following drying at room temperature, stained cells were counted manually. The colony formation rate (\%) was calculated according to the following formula: (Number of clones/number of cells inoculated) x100.

Flow cytometry. The Annexin V-FITC Apoptosis Detection Kit (cat. no. C1062M; Beyotime Institute of Biotechnology) was used to assess cell apoptosis. SiHa or HeLa cell $\left(3 \times 10^{5}\right.$ cells) suspensions were prepared using PBS. Subsequently, cells were incubated with $5 \mu 1$ Annexin V-FITC and $10 \mu \mathrm{l}$ PI (cat. no. C1062M; Beyotime Institute of Biotechnology) for $20 \mathrm{~min}$ in the dark at room temperature. Apoptotic cells (early and late apoptotic cells) were analyzed using a CytoFLEX flow cytometer (Beckman Coulter, Inc.) and analyzed using FlowJo (version 10.0; FlowJo LLC).

Wound healing assay. SiHa and HeLa cell migration was detected by performing wound healing assays. Cells were seeded $\left(5 \times 10^{5}\right.$ cells/well) into a 6 -well plate and incubated overnight at $37^{\circ} \mathrm{C}$. At $80 \%$ confluence, a pipette was used to create a single wound in the cell monolayer. Following washing using PBS, cells were incubated with serum-free DMEM medium at $37^{\circ} \mathrm{C}$ with $5 \% \mathrm{CO}_{2}$. SiHa and HeLa cell migration was observed at 0 and $24 \mathrm{~h}$ using a TS100 light microscope (Nikon Corporation; magnification, x100). The relative migration distance was calculated according to the following formula: (wound width at $0 \mathrm{~h}$-wound width at $24 \mathrm{~h}$ )/wound width at $0 \mathrm{~h}$. Relative migration rates were calculated as the ratio of the relative migration distance of cells in the ILF3-AS1 group to the relative migration distance of cells in the blank group.

Transwell invasion assay. Transwell invasion assays were performed to assess $\mathrm{SiHa}$ and HeLa cell invasion. The upper chambers of Transwell inserts (pore size, $8 \mu \mathrm{m}$; BD Biosciences) were coated with Matrigel for $30 \mathrm{~min}$ at $37^{\circ} \mathrm{C}$. Subsequently, cells were seeded $\left(1 \times 10^{4}\right.$ cells/well $)$ into the upper chamber with serum-free DMEM. DMEM supplemented with $10 \%$ FBS was added into the lower chamber. Following incubation for $48 \mathrm{~h}$ at $37^{\circ} \mathrm{C}$, invading cells were fixed with 4\% paraformaldehyde (cat. no. C104188-500g; Shanghai Aladdin Biochemical Technology Co., Ltd.) at room temperature for $5 \mathrm{~min}$ and stained with $0.1 \%$ crystal violet (cat. no. RBG1019-1; Guangzhou Rolls Biotechnology Co., Ltd.) for $15 \mathrm{~min}$ at room temperature. Invading cells were observed using a light microscope (magnification, x100).

Western blotting. Following washing with PBS, total protein was isolated from $\mathrm{SiHa}$ and $\mathrm{HeLa}$ cells using $100 \mu \mathrm{l}$ cell lysis buffer (RIPA buffer; cat. no. 9806; Cell Signaling Technology, Inc.). Proteins were obtained from the cell lysate by centrifugation at $4^{\circ} \mathrm{C}$ for $10 \mathrm{~min}$ at $1,600 \mathrm{x} \mathrm{g}$. Protein concentrations were determined using the BCA method. Proteins $(100 \mu \mathrm{g})$ were separated via $10 \%$ SDS-PAGE and transferred to PVDF membranes. Following washing three times with 1X TBST $(0.5 \%$ Tween-20) for $10 \mathrm{~min}$, the membranes were blocked with $5 \%$ skimmed milk for $1.5 \mathrm{~h}$ at room temperature. Subsequently, the membranes were incubated overnight at $4^{\circ} \mathrm{C}$ with primary antibodies targeted against the following: E-Cadherin (E-Cad; 1:1,000; cat. no. 14472; Cell Signaling Technology, Inc.), N-Cadherin (N-Cad; 1:1,000; cat. no. 14215; Cell Signaling Technology, Inc.), snail family transcriptional repressor 1 (Snail; 1:10,000; cat. no. ab53519; Abcam) and GAPDH (1:10,000; cat. no. ab8245; Abcam). Following primary incubation, the membranes were incubated with anti-goat (HRP-conjugated; 1:5,000; cat. no. ab6885; Abcam) and anti-mouse (HRP-conjugated; 1:10,000; cat. no. ab6728; Abcam) secondary antibodies for $1 \mathrm{~h}$ at $37^{\circ} \mathrm{C}$. The membranes were washed three times. Protein bands were visualized using ECL luminescent liquid (cat. no. RBG2019-1; Guangzhou 


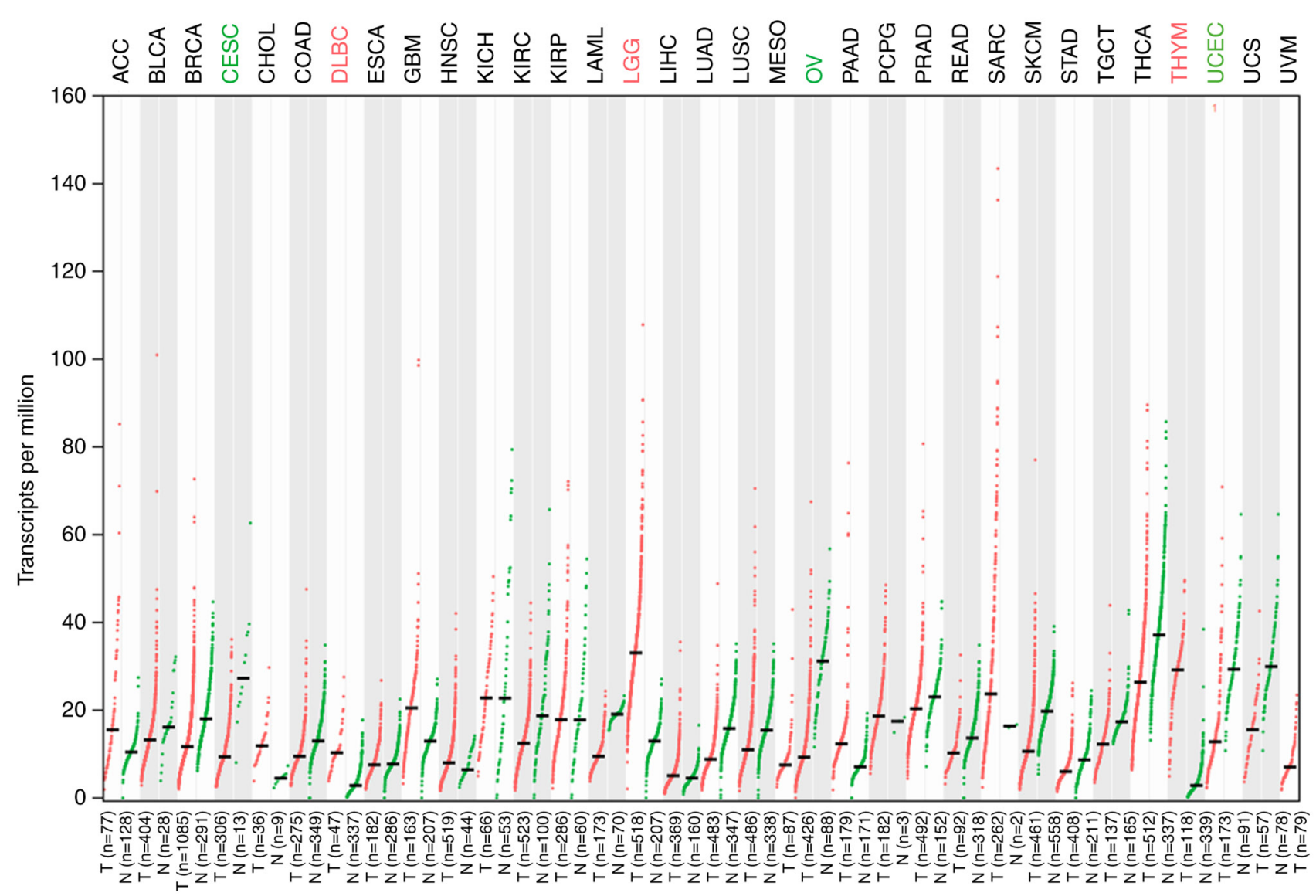

Figure 1. Gene Expression Profiling Interactive Analysis database analysis of ILF3-AS1 expression levels in tumor tissues. Red dots represent the transcripts levels of ILF3-AS1 in tumor tissues. Green dots represent the transcripts levels of ILF3-AS1 in healthy tissues. Green text indicates the tumours with the lowest ILF3-AS1 expression. Red text indicates the tumours with the highest ILF3-AS1 expression. ILF3-AS1, ILF3 divergent transcript; T, tumor; N, healthy.

Rolls Biotechnology Co., Ltd.) and observed using a GelDoc XR gel imager (Bio-Rad Laboratories, Inc.). Protein expression levels were semi-quantified using ImageJ software (version 1.47; National Institutes of Health) with GAPDH as the loading control.

Statistical analysis. Statistical analyses were performed using SPSS software (version 23.0; IBM Corp.). Data are presented as the mean $\pm \mathrm{SD}$. All experiments were repeated three times. For normally distributed data, comparisons between two groups were analyzed using an unpaired Student's t test, whereas comparisons among multiple groups were analyzed using one-way ANOVA followed by Bonferroni's post hoc test. Pearson's correlation coefficient was used to analyze correlations. $\mathrm{P}<0.05$ was considered to indicate a statistically significant difference.

\section{Results}

ILF3-AS1 expression is downregulated in CC tissues. ILF3-AS1 expression in tumor tissues was detected using the GEPIA database (Fig. 1). The results demonstrated that ILF3-AS1 was expressed at lower levels in tumor tissues compared with healthy tissues. In addition, the GEPIA database predicted that ILF3-AS1 expression levels were significantly lower in CC tissues compared with healthy tissues $(\mathrm{P}<0.05$; Fig. 2A). Moreover, low ILF3-AS1 expression levels were significantly associated with more advanced stages of $\mathrm{CC}(\mathrm{F}=2.71 ; \operatorname{Pr}(>\mathrm{F})=0.0453$; Fig. $2 \mathrm{~B})$. The overall survival of patients with low ILF3-AS1 expression was significantly worse compared with patients with high ILF3-AS1 expression $(\mathrm{P}=0.0089 ; \mid \log 2 \mathrm{FCl}$ cutoff=1; Fig. 2C). In addition, ILF3-AS1 expression levels in CC tissues of different stages and ANTs were detected via RT-qPCR ( $<<0.001$; Fig. 2D). ILF3-AS1 expression was significantly downregulated in CC tissues compared with ANTs, and was significantly lower in stage III/IV CC tissues compared with stage I/II CC tissues $(\mathrm{P}<0.001)$. The results demonstrated that lncRNA ILF3-AS1 was expressed at lower levels in CC tissues compared with ANTs, and that ILF3-AS1 expression in stage III/IV CC tissues was decreased compared with stage I/II CC tissues.

ILF3-AS1 inhibits CC cell proliferation and promotes $C C$ cell apoptosis. ILF3-AS1 expression levels in CC cells were detected via RT-qPCR. The results demonstrated that ILF3-AS1 expression was significantly downregulated in CC cells compared with NCEs ( $\mathrm{P}<0.001$; Fig. 3A). Compared with NCEs, SiHa and HeLa cells displayed the lowest expression levels of ILF3-AS1 among the CC cell lines, thus were used for subsequent experiments. Following transfection with ILF3-AS1, ILF3-AS1 expression levels were significantly increased in $\mathrm{SiHa}$ and HeLa cells compared with the NC group ( $\mathrm{P}<0.001$; Fig. 3B and C). Compared with the NC group, ILF3-AS1 overexpression significantly inhibited SiHa and 
A
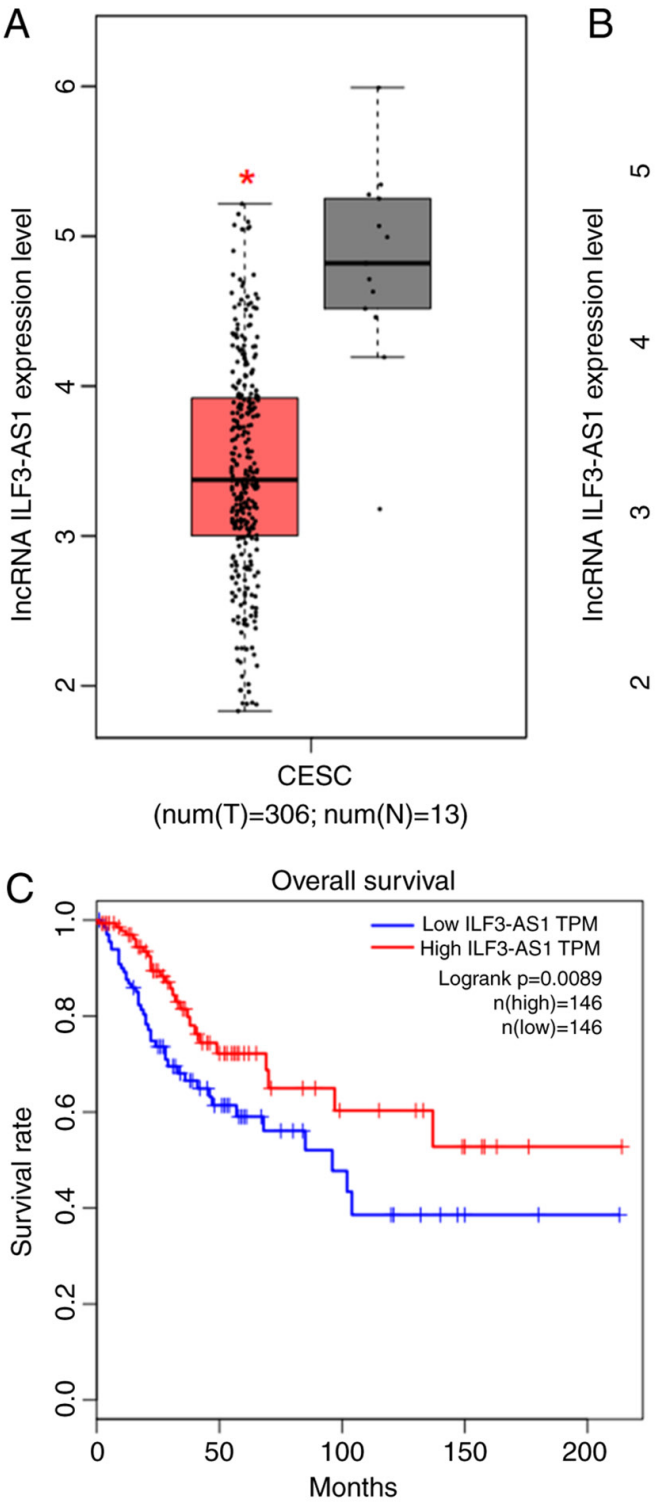

$\mathrm{B}$

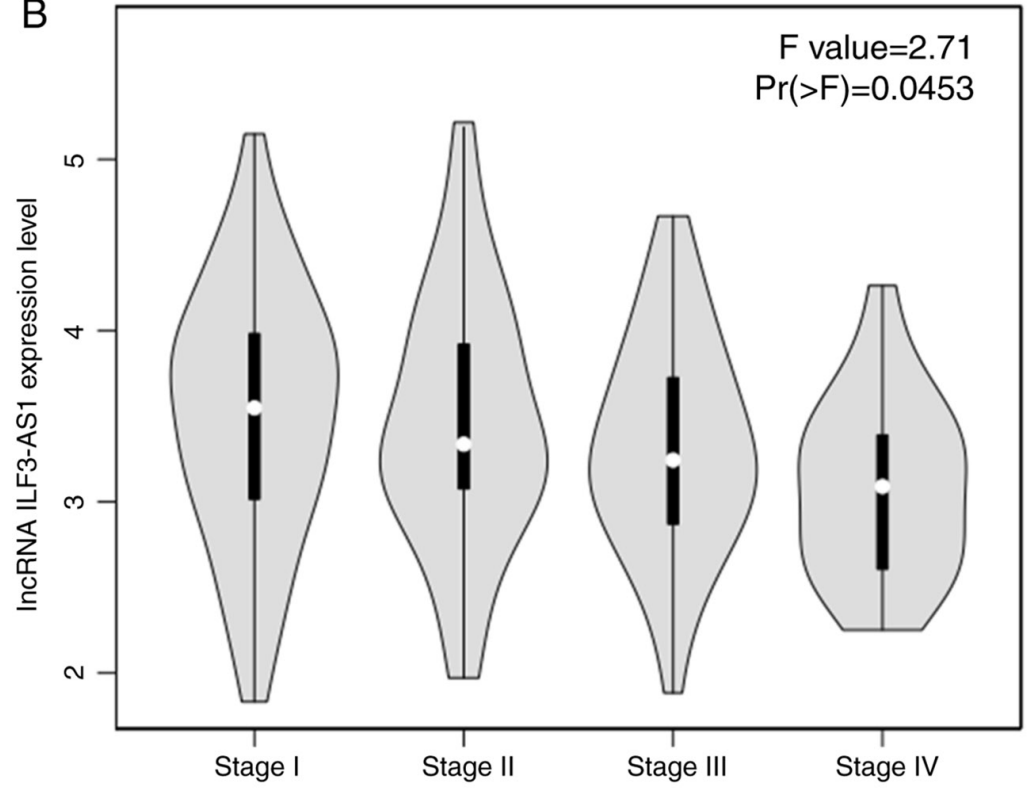

$\mathrm{D}$

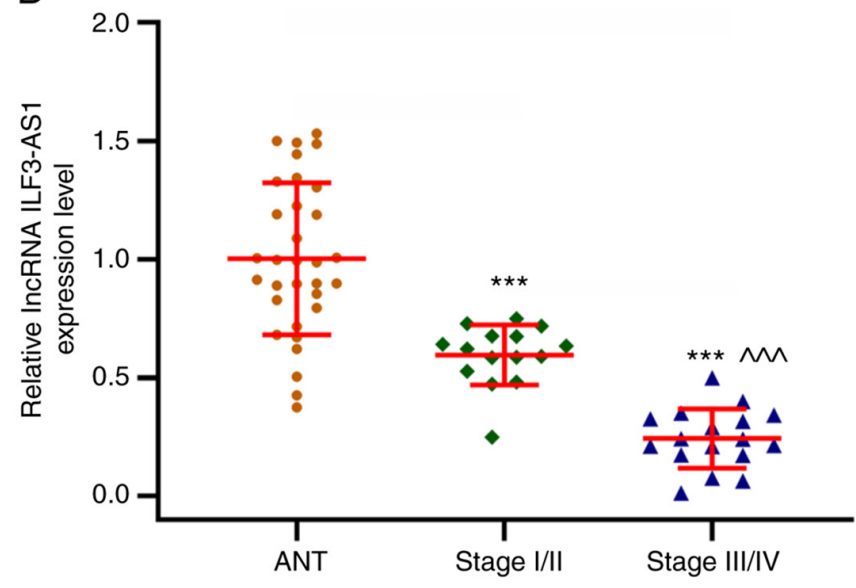

Figure 2. ILF3-AS1 expression is downregulated in CC tissues. (A) GEPIA database analysis demonstrated that ILF3-AS1 expression was downregulated in CC tissues compared with healthy tissues. The red box represents CC tissues and the gray box represents healthy tissues. (B) Low ILF3-AS1 expression levels were associated with the stage of CC. (C) GEPIA database analysis of overall survival in patients with CC. (D) Reverse transcription-quantitative PCR was performed to measure ILF3-AS1 expression levels in CC tissues (stage I/II=15; stage III/IV=17) and ANTs (n=32). All experiments were repeated three times. ${ }^{*} \mathrm{P}<0.05$ and ${ }^{* * * *} \mathrm{P}<0.001$ vs. healthy tissues or ANTs; ${ }^{\wedge \wedge} \mathrm{P}<0.001$ vs. stage I/II. ILF3-AS1, ILF3 divergent transcript; CC, cervical cancer; GEPIA, Gene Expression Profiling Interactive Analysis; ANT, adjacent tissue; lncRNA, long non-coding RNA; CESC, cervical and endocervical cancer; T, tumor; $\mathrm{N}$, healthy; TPM, transcripts per million.

HeLa cell viability at 48 and $72 \mathrm{~h}(\mathrm{P}<0.05$, Fig. 3D and E). Similarly, ILF3-AS1 overexpression significantly decreased $\mathrm{SiHa}$ and HeLa cell proliferation compared with the NC group $(\mathrm{P}<0.001$; Fig. 3F and $\mathrm{G})$. The flow cytometry results indicated that ILF3-AS1 overexpression significantly increased cell apoptosis compared with the NC group $(\mathrm{P}<0.001$; Fig. 3H and I). Thus, the results demonstrated that ILF3-AS1 was expressed at lower levels in CC cells compared with NCEs, and ILF3-AS1 overexpression inhibited cell viability and promoted cell apoptosis compared with the NC group.

ILF3-AS1 inhibits CC metastasis by inhibiting epithelialmesenchymal transition (EMT). SiHa and HeLa cell migration and invasion were also assessed (Fig. 4A-D). In ILF3-AS1-overexpression cells, cell migration and invasion were significantly inhibited compared with the NC group $(\mathrm{P}<0.001$; Fig. 4A-D). To further explore the mechanism underlying ILF3-AS1-mediated alterations, the expression levels of EMT-associated proteins were detected. ILF3-AS1 overexpression significantly upregulated E-Cad expression levels, and significantly downregulated N-Cad and Snail expression levels in $\mathrm{SiHa}$ and HeLa cells compared with the NC group $(\mathrm{P}<0.001$; Fig. 4E and $\mathrm{F})$. The aforementioned results indicated that ILF3-AS1 overexpression inhibited EMT in CC cells.

miR-454-3p is highly expressed in CC cells and is negatively correlated with ILF3-AS1. StarBase predicted that miR-454-3p was a target miRNA of ILF3-AS1, which was verified by performing dual-luciferase reporter assays ( $\mathrm{P}<0.001$; Fig. 5A-C). 

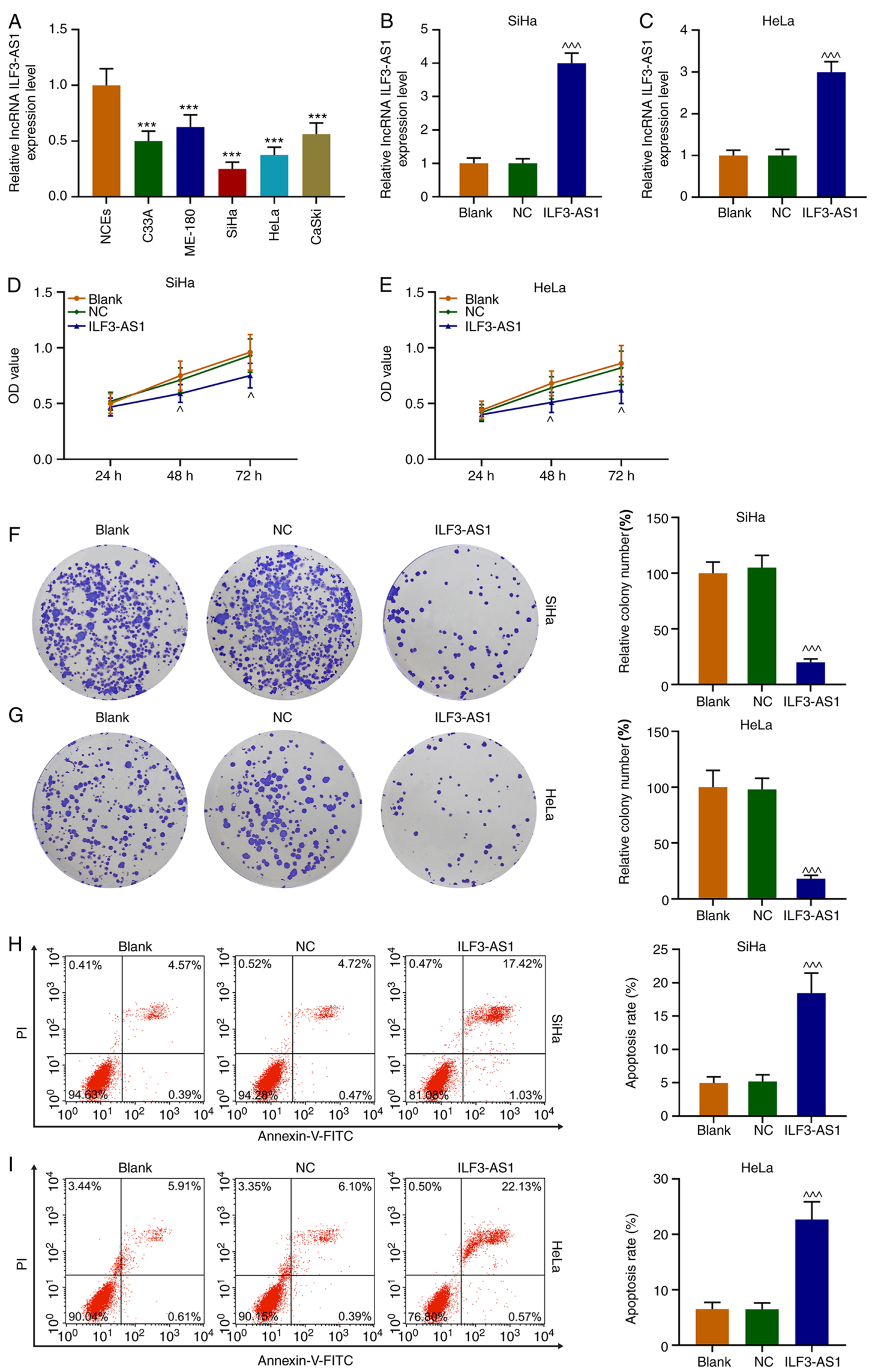

Figure 3. ILF3-AS1 inhibits CC cell proliferation and promotes CC cell apoptosis. (A) ILF3-AS1 expression levels in NCEs and CC cells were detected via RT-qPCR. Transfection efficiency of ILF3-AS1 in (B) SiHa and (C) HeLa cells. (D) SiHa and (E) HeLa cell viability were assessed by performing Cell Counting Kit-8 assays. (F) SiHa and (G) HeLa cell proliferation were assessed by conducting cell colony formation assays (magnification, x1). (H) SiHa and (I) HeLa cell apoptosis was assessed via flow cytometry. All experiments were repeated three times. ${ }^{* * *} \mathrm{P}<0.001$ vs. NCEs; ${ }^{\wedge} \mathrm{P}<0.05$ and ${ }^{\wedge \wedge} \mathrm{P}<0.001$ vs. NC. ILF3-AS1, ILF3 divergent transcript; CC, cervical cancer; NCE, normal cervical epithelial cell line; RT-qPCR, reverse transcription-quantitative PCR; NC, negative control; lncRNA, long non-coding RNA; OD, optical density. 
A
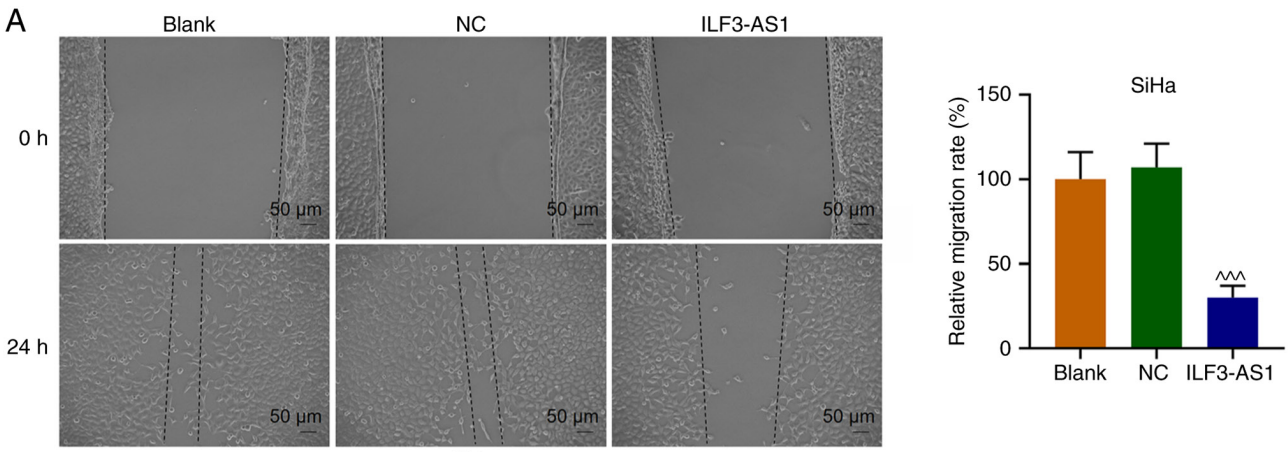

B

Blank

$\mathrm{SiHa}$

ILF3-AS1
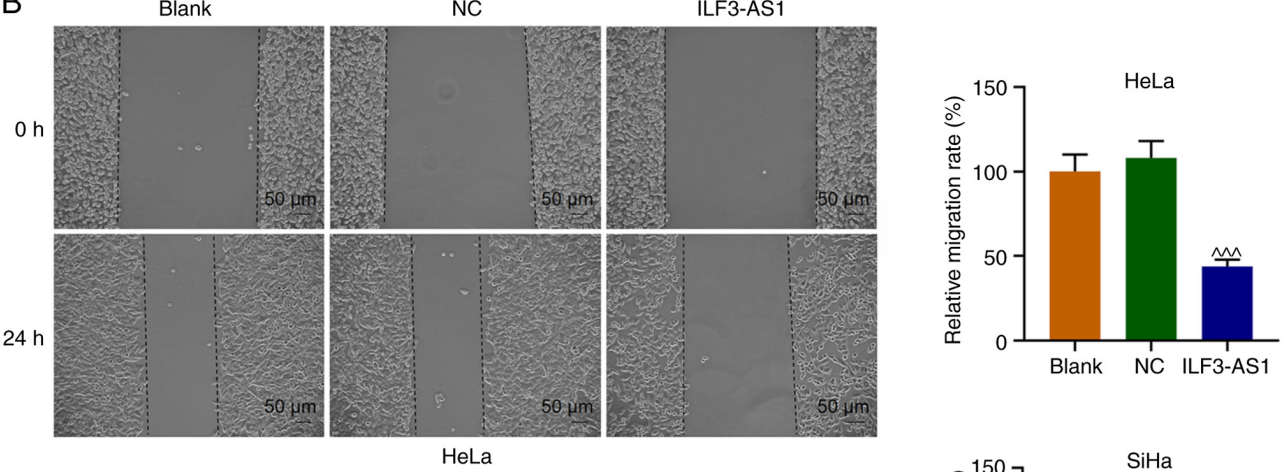

C

Blank

NC

ILF3-AS1
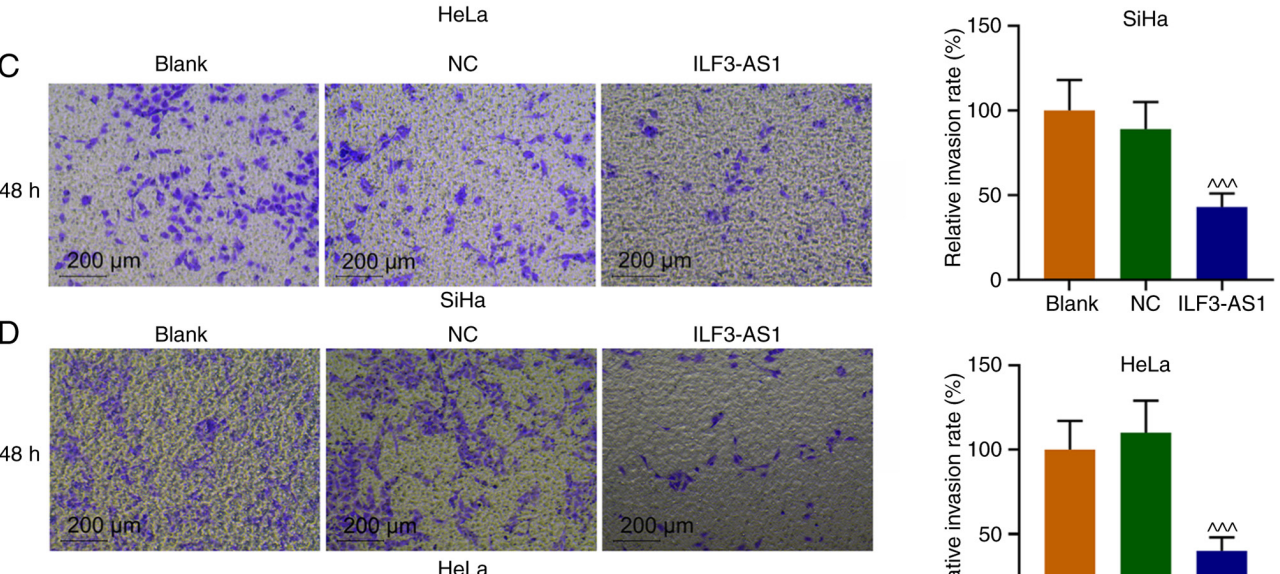

$\mathrm{D}$

ILF3-AS1

E
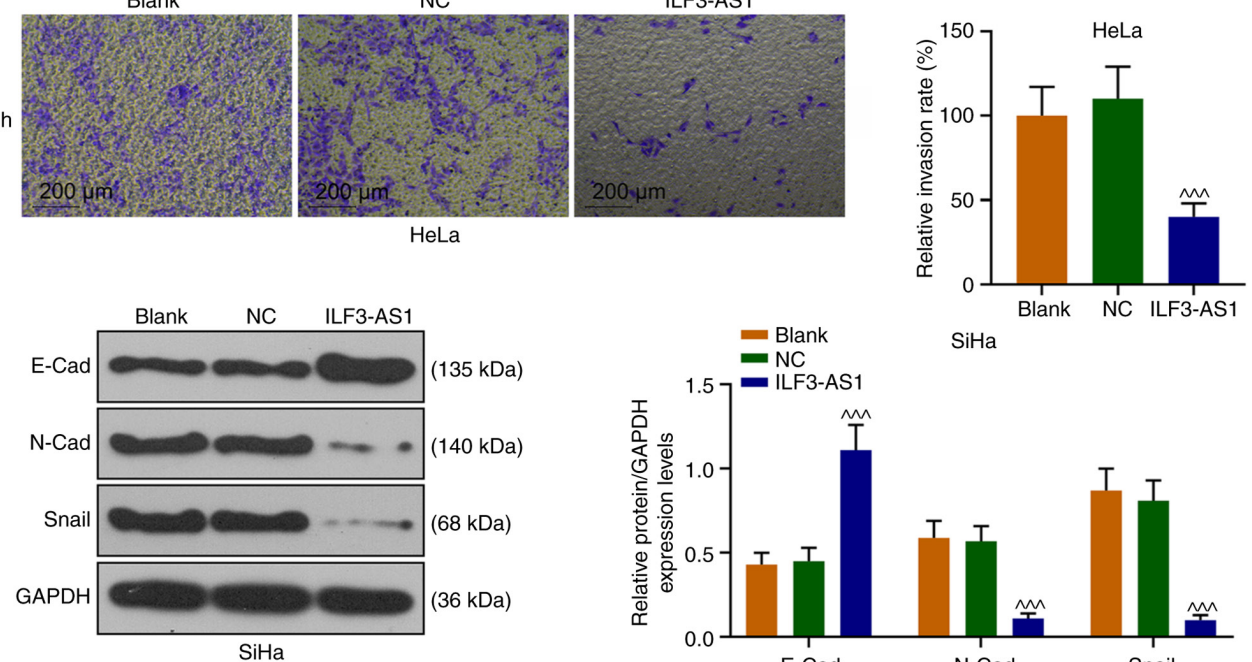

F
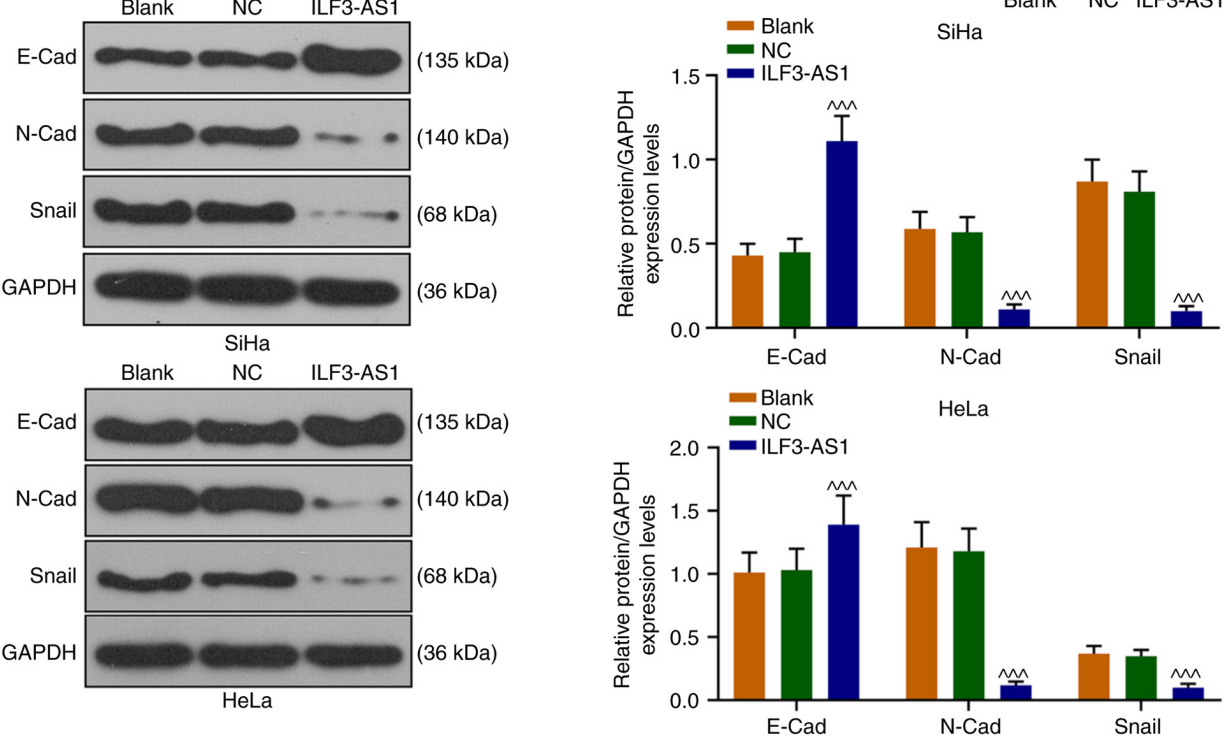

Figure 4. ILF3-AS1 inhibits CC metastasis by inhibiting EMT. (A) SiHa and (B) HeLa cell migration were assessed by performing the wound healing assay. (C) SiHa and (D) HeLa cell invasion were assessed by conducting the Transwell invasion assay. Expression levels of EMT-associated proteins in (E) SiHa and (F) HeLa cells were determined via western blotting. All experiments were repeated three times. ${ }^{\wedge \wedge} \mathrm{P}<0.001$ vs. NC. ILF3-AS1, ILF3 divergent transcript; CC, cervical cancer; EMT, epithelial-mesenchymal transition; NCE, normal cervical epithelial cell line; NC, negative control; E-cad, E-cadherin; N-cad, $\mathrm{N}$-cadherin; Snail, snail family transcriptional repressor 1. 

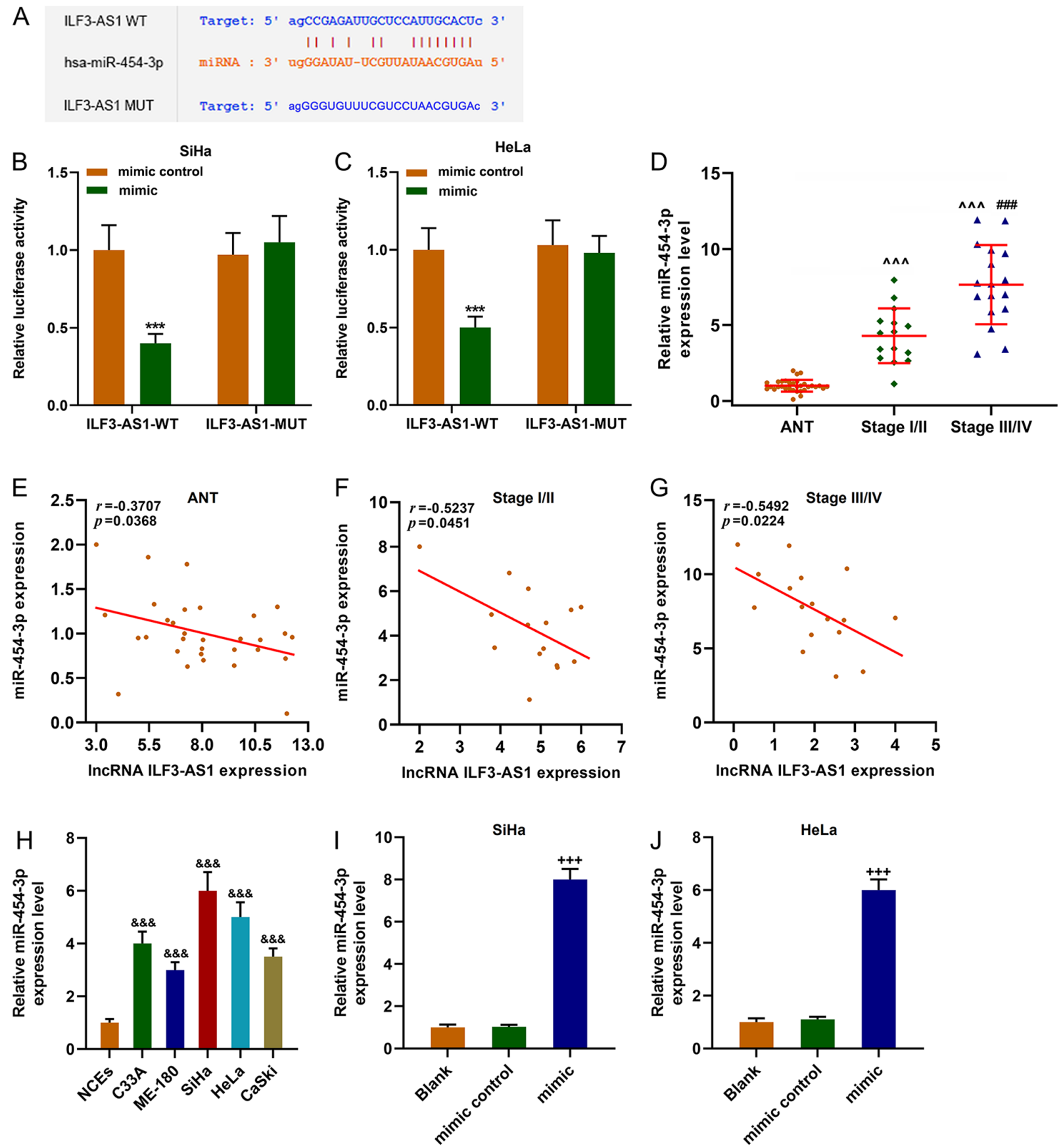

Figure 5. miR-454-3p expression is upregulated in CC cells and is negatively correlated with ILF3-AS1. (A) StarBase predicted that miR-454-3p was the targeted miRNA of ILF3-AS1. The sequences of ILF3-AS1 WT, ILF3-AS1 MUT and miR-454-3p. Dual-luciferase reporter assays were performed to verify the relationship between ILF3-AS1 and miR-454-3p in (B) SiHa and (C) HeLa cells. (D) RT-qPCR was performed to measure miR-454-3p expression levels in ANTs and CC tissues. Pearson's correlation coefficient was used to analyze the correlation between miR-454-3p and ILF3-AS1 expression in (E) ANTs, (F) stage I/II CC tissues and (G) stage III/IV CC tissues. (H) RT-qPCR was performed to measure miR-454-3p expression levels in NCEs and CC cells. Transfection efficiency of miR-454-3p mimic in (I) SiHa and (J) HeLa cells. All experiments were repeated three times. ${ }^{* * * *} \mathrm{P}<0.001$ vs. mimic control; ${ }^{\wedge \wedge} \mathrm{P}<0.001 \mathrm{vs}$. ANT; ${ }^{\# \# "} \mathrm{P}<0.001$ vs. stage I/II; ${ }^{\& \& \&} \mathrm{P}<0.001$ vs. NCEs; ${ }^{++} \mathrm{P}<0.001$ vs. blank. miR/miRNA, microRNA; CC, cervical cancer; ILF3-AS1, ILF3 divergent transcript; WT, wild-type; MUT, mutant; RT-qPCR, reverse transcription-quantitative PCR; ANT, adjacent tissue; NCE, normal cervical epithelial cell line.

miR-454-3p expression was significantly upregulated in CC tissues and cells compared with ANTs and NCEs, respectively ( $\mathrm{P}<0.001$; Fig. 5D and H). miR-454-3p expression levels were significantly higher in stage III/IV CC tissues compared with stage I/II CC tissues ( $\mathrm{P}<0.001$; Fig. 5D). Moreover, the results indicated that ILF3-AS1 and miR-454-3p expression levels were negatively correlated $(\mathrm{P}<0.05 ; \mathrm{r}<0$; Fig. 5E-G). miR-454-3p mimic significantly upregulated miR-454-3p expression levels in $\mathrm{SiHa}$ and HeLa cells compared with the mimic control group $(\mathrm{P}<0.001$; Fig. 5I and J).

PTEN is expressed at low levels in CC cells, and is negatively correlated with miR-454-3p and positively correlated with ILF3-AS1. TargetScan predicted that the target gene for miR-454-3p was PTEN, which was further verified by performing dual-luciferase reporter assays $(\mathrm{P}<0.001$; 

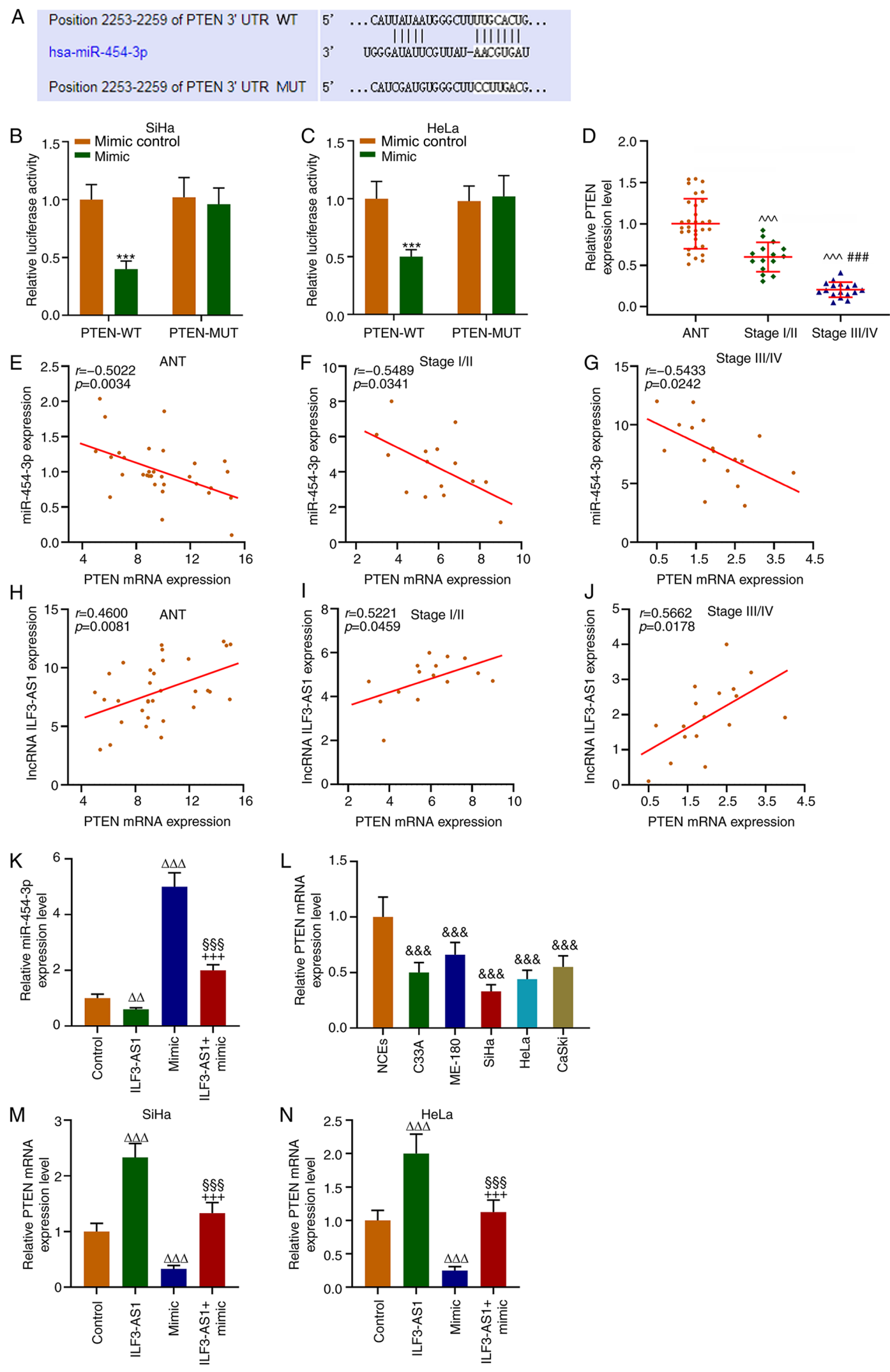

Figure 6. PTEN is a target gene for miR-454-3p and is correlated with miR-454-3p and ILF3-AS1 expression. (A) TargetScan was used to predict the target gene of miR-454-3p. Dual-luciferase reporter assays were performed to verify the relationship between PTEN and miR-454-3p in (B) SiHa and (C) HeLa cells. (D) RT-qPCR was performed to measure miR-454-3p expression levels in ANTs and CC tissues. Pearson's correlation coefficient was used to analyze the correlation between miR-454-3p and PTEN expression in (E) ANT, (F) stage I/II CC tissues and (G) stage III/IV CC tissues. Pearson's correlation coefficient was used to analyze the correlation between PTEN and ILF3-AS1 in (H) ANTs, (I) stage I/II CC tissues and (J) stage III/IV CC tissues. RT-qPCR was performed to measure (K) miR-454-3p expression levels in SiHa cells following transfection, (L) PTEN expression levels in NCEs and CC cells, and PTEN expression levels in (M) SiHa and $(\mathrm{N})$ HeLa cells following transfection. All experiments were repeated three times. ${ }^{* * * *} \mathrm{P}<0.001 \mathrm{vs}$. mimic control; ${ }^{\wedge \wedge} \mathrm{P}<0.001$ vs. ANT; ${ }^{\# \# ~} \mathrm{P}<0.001$ vs. stage I/II; \&\&\& $\mathrm{P}<0.001$ vs. NCEs; ${ }^{\Delta} \mathrm{P}<0.01 ;{ }^{\Delta \Delta} \mathrm{P}<0.001$ vs. control; ${ }^{\$ \$} \mathrm{P}<0.001$ vs. ILF3-AS1; ${ }^{+++} \mathrm{P}<0.001$ vs. miR-454-3p mimic. miR, microRNA; ILF3-AS1, ILF3 divergent transcript; RT-qPCR, reverse transcription-quantitative PCR; ANT, adjacent tissue; CC, cervical cancer; NCE, normal cervical epithelial cell line; WT, wild-type; MUT, mutant; UTR, untranslated region. 
Fig. 6A-C). The RT-qPCR results demonstrated that PTEN expression levels were significantly lower in $\mathrm{CC}$ tissues and cells compared with ANTs and NECs, respectively $(\mathrm{P}<0.001$; Fig. 6D and L). In addition, PTEN expression levels in stage III/IV CC tissues were significantly lower compared with stage I/II CC tissues $(\mathrm{P}<0.001$; Fig. 6D). Correlation analysis demonstrated that PTEN expression was negatively correlated with miR-454-3p expression ( $\mathrm{P}<0.05$; $\mathrm{r}=-0.5022$; Fig. 6E-G), but positively correlated with ILF3-AS1 expression $(\mathrm{P}<0.05$; $\mathrm{r}=0.4600$; Fig. $6 \mathrm{H}-\mathrm{J})$. In addition, $\mathrm{CC}$ cells were transfected with ILF3-AS1, miR-454-3p mimic or ILF3-AS1 + miR-454-3p mimic. miR-454-3p expression levels in $\mathrm{SiHa}$ cells were significantly decreased by ILF3-AS1 overexpression compared with the control group, which was significantly reversed by co-transfection miR-454-3p mimic $(\mathrm{P}<0.01$; Fig. $6 \mathrm{~K})$. Compared with the control group, miR-454-3p mimic significantly downregulated PTEN expression levels, but ILF3-AS1 overexpression significantly upregulated PTEN expression levels, which was significantly reversed by co-transfection with miR-454-3p mimic ( $\mathrm{P}<0.001$; Fig. 6M and $\mathrm{N})$. The results indicated that ILF3-AS1 upregulated PTEN gene expression by negatively regulating miR-454-3p.

\section{Discussion}

It has been reported that ILF3-AS1 can be used to predict survival in patients with CC $(25,26)$. However, the functions and mechanism underlying ILF3-AS1 in CC are not completely understood. The present study demonstrated that ILF3-AS1 overexpression significantly inhibited CC cell migration and invasion compared with the $\mathrm{NC}$ group. Therefore, the expression levels of EMT-related factors were measured. E-Cad, $\mathrm{N}-\mathrm{Cad}$ and Snail are important regulators of EMT (31). Downregulation or deletion of E-Cad protein can cause tumor cell release contact inhibition, and the conversion of E-Cad to $\mathrm{N}$-Cad can enhance tumor cell migration and invasion, which promotes EMT (32-34). Snail downregulates the expression levels of epithelial phenotype genes by binding to the E-box sequence of the target gene (35). The present study demonstrated that compared with the NC group, ILF3-AS1 overexpression significantly upregulated E-Cad protein expression levels, and significantly downregulated $\mathrm{N}-\mathrm{Cad}$ and Snail expression levels, which indicated that ILF3-AS1 overexpression inhibited CC cell EMT. EMT, a biological process by which epithelial cells are transformed into mesenchymal cells (36), serves an important role in epithelial-derived cancer cell migration and invasion (37). Therefore, investigating the molecular mechanism underlying EMT in the occurrence, development and metastasis of tumors, and developing diagnostic and molecular therapeutic strategies based on EMT may improve $\mathrm{CC}$ treatment.

lncRNAs affect tumor cell proliferation by inhibiting miRNA expression (38). IncRNAs can compete with miRNAs for binding to genes, and can also cleave precursors of miRNAs in cells or directly inhibit miRNA expression (39). In the present study, starBase predicted that miR-454-3p was a target miRNA of ILF3-AS1. miR-454-3p serves a regulatory role in a variety of neoplastic diseases, including breast and bladder cancer $(40,41)$. Wang et al (42) reported that miR-454-3p is expressed at low levels in bladder cancer cells, which negatively regulated cell invasion and migration by targeting ZEB2 antisense RNA 1. Shao et al (43) demonstrated that miR-454-3p is an exosome biomarker, and miR-454-3p overexpression inhibits glioma cell proliferation, migration, invasion and autophagy. However, Ren et al (40) reported that inhibition of regulation of nuclear pre-mRNA domain containing $1 \mathrm{~A}$ by miR-454-3p activates the $\mathrm{Wnt} / \beta$-catenin signaling pathway, thereby promoting breast cancer metastasis and growth (40). In addition, miR-454-3p expression is upregulated in colorectal cancer tissues and participates in the development of colorectal cancer by promoting liver cancer cell proliferation, invasion and migration (44). The aforementioned studies suggested that miR-454-3p might display different effects in different types of cancer. To explore the role of miR-454-3p in CC, miR-454-3p expression levels in $\mathrm{CC}$ tissues and cells were measured. The results demonstrated that miR-454-3p expression levels were significantly increased in CC tissues and cells compared with ANTs and NCEs, respectively. Moreover, miR-454-3p was identified as a target miRNA of ILF3-AS1, and its expression was negatively regulated by ILF3-AS1.

In the present study, TargetScan also identified an interaction between miR-454-3p and PTEN. PTEN, which is $200 \mathrm{~kb}$ in length and is located on the human chromosome 10q23.3 (45), displays a variety of biological activities and encodes a dual phosphatase with lipid and protein phosphatase activities (46). Previous studies demonstrated that PTEN inhibits cell proliferation, migration and adhesion, induces apoptosis, and participates in embryonic development and other physiological functions via multiple signaling pathways, including the Akt signaling pathway $(47,48)$. PTEN is a tumor suppressor gene and one of the most susceptible genes in tumors (46). By inhibiting FAK expression activity, PTEN reduces integrin-mediated cell proliferation and local adhesion, thereby inhibiting tumor cell migration and invasion (49). In addition, PTEN can suppress the phosphorylation of ERK, RAS and SHC adaptor protein 1 , which are upstream of the MAPK/ERK signaling pathway, thereby inhibiting tumor cell proliferation (50). Therefore, the aforementioned studies indicated that increased PTEN expression levels display a significant inhibitory effect on tumor cell migration and invasion. The results of the present study demonstrated that PTEN expression was significantly decreased in CC cells compared with NCEs, which was partially reversed by ILF3-AS1 overexpression. Moreover, miR-454-3p negatively regulated ILF3-AS1.

In conclusion, the present study demonstrated that ILF3-AS1 was expressed at significantly lower levels in CC tissues and cells compared with ANTs and NCEs, respectively. Compared with the NC group, ILF3-AS1 overexpression significantly inhibited CC cell viability, reduced CC cell migration and invasion, and promoted CC cell apoptosis by inhibiting EMT. Moreover, compared with the control group, ILF3-AS1 overexpression significantly upregulated the expression levels of the tumor suppressor gene PTEN by negatively regulating miR-454-3p. Therefore, the results of the present study may aid with improving the treatment of CC.

\section{Acknowledgements}

Not applicable. 


\section{Funding}

The present study was supported by the Medical Scientific Research Foundation of Guangdong Province (grant no. B2020211), the Scientific Research Project of Guangdong Provincial Bureau of Traditional Chinese Medicine (grant no. 20201284) and the Guangzhou Health Science and Technology Project (grant no. 20202A010024).

\section{Availability of data and materials}

The datasets analyzed during the current study are available from the corresponding author on reasonable request.

\section{Authors' contributions}

LZ and RC substantially contributed to the conception and design of the present study. CJ, QX, WZ, XG and HH acquired, analyzed and interpreted the data. $\mathrm{LZ}$ and $\mathrm{RC}$ drafted the manuscript and critically revised it for important intellectual content. All authors read and approved the final manuscript.

\section{Ethics approval and consent to participate}

All patients provided written informed consent. The study was approved by Guangdong Clifford Hospital (approval no. 2014007XHK).

\section{Patient consent for publication}

Not applicable.

\section{Competing interests}

The authors declare that they have no competing interests.

\section{References}

1. Burki TK: Novel mutations in cervical cancer. Lancet Oncol 18: e137, 2017.

2. Bychkovsky BL, Ferreyra ME, Strasser-Weippl K, Herold CI, de Lima Lopes G Jr, Dizon DS, Schmeler KM, Del Carmen M, Randall TC, Nogueira-Rodrigues A, et al: Cervical cancer control in Latin America: A call to action. Cancer 122: 502-514, 2016.

3. Arbyn, M, Weiderpass, E, Bruni, L, de Sanjosé, S, Saraiya, M, Ferlay, J and Bray, F: Estimates of incidence and mortality of cervical cancer in 2018: a worldwide analysis. Lancet Glob Health 8: e191-e203, 2020.

4. Fang J, Zhang $\mathrm{H}$ and Jin S: Epigenetics and cervical cancer: From pathogenesis to therapy. Tumour Biol 35: 5083-5093, 2014

5. Kanyina EW, Kamau L and Muturi M: Cervical precancerous changes and selected cervical microbial infections, Kiambu County, Kenya, 2014: A cross sectional study. BMC Infect Dis 17: 647, 2017.

6. Tavakoli F, Khatami SS, Momeni F, Azadbakht J and Ghasemi F Cervical cancer diagnosis: Insights into biochemical biomarkers and Imaging techniques. Comb Chem High Throughput Screen: Aug 31, 2020 (Epub ahead of print).

7. zur Hausen H: Papillomaviruses and cancer: From basic studies to clinical application. Nat Rev Cancer 2: 342-350, 2002.

8. zur Hausen H: Papillomaviruses in the causation of human cancers-a brief historical account. Virology 384: 260-265, 2009.

9. Gillison ML: Human papillomavirus-related diseases: Oropharynx cancers and potential implications for adolescent HPV vaccination. J Adolesc Health 43 (Suppl 4): S52-S60, 2008.

10. Mattick JS and Makunin IV: Non-coding RNA. Hum Mol Genet 15: R17-R29, 2006.
11. Hombach S and Kretz M: Non-coding RNAs: Classification, biology and functioning. Adv Exp Med Biol 937: 3-17, 2016.

12. Cabianca DS, Casa V and Gabellini D: A novel molecular mechanism in human genetic disease: A DNA repeat-derived IncRNA. RNA Biol 9: 1211-1217, 2012.

13. Jarroux J, Morillon A and Pinskaya M: History, discovery, and classification of lncRNAs. Adv Exp Med Biol 1008: 1-46, 2017.

14. Kim J, Piao HL, Kim BJ, Yao F, Han Z, Wang Y, Xiao Z, Siverly AN, Lawhon SE, Ton BN, et al: Long noncoding RNA MALAT1 suppresses breast cancer metastasis. Nat Genet 50: 1705-1715, 2018.

15. Wang Y, He L, Du Y, Zhu P, Huang G, Luo J, Yan X, Ye B, $\mathrm{Li} \mathrm{C}$, Xia P, et al: The long noncoding RNA lncTCF7 promotes self-renewal of human liver cancer stem cells through activation of Wnt signaling. Cell Stem Cell 16: 413-425, 2015.

16. Hu X, Feng Y, Zhang D, Zhao SD, Hu Z, Greshock J, Zhang Y, Yang L, Zhong X, Wang LP, et al: A functional genomic approach identifies FAL1 as an oncogenic long noncoding RNA that associates with BMI1 and represses p21 expression in cancer. Cancer Cell 26: 344-357, 2014.

17. Wu WJ, Shen Y, Sui J, Li CY, Yang S, Xu SY, Zhang M, Yin LH, $\mathrm{Pu}$ YP and Liang GY: Integrated analysis of long non-coding RNA competing interactions revealed potential biomarkers in cervical cancer: Based on a public database. Mol Med Rep 17: 7845-7858, 2018.

18. Luan X and Wang Y: LncRNA XLOC_006390 facilitates cervical cancer tumorigenesis and metastasis as a ceRNA against miR-331-3p and miR-338-3p. J Gynecol Oncol 29: e95, 2018.

19. Liu Y, Yang Y, Li L, Liu Y, Geng P, Li G and Song H: LncRNA SNHG1 enhances cell proliferation, migration, and invasion in cervical cancer. Biochem Cell Biol 96: 38-43, 2018.

20. Chen X, Liu S, Zhao X, Ma X, Gao G, Yu L, Yan D, Dong H and Sun W: Long noncoding RNA ILF3-AS1 promotes cell proliferation, migration, and invasion via negatively regulating miR-200b/a/429 in melanoma. Biosci Rep 37: BSR20171031, 2017.

21. Gao G, Li W, Liu S, Han D, Yao X, Jin J, Han D, Sun W and Chen X: The positive feedback loop between ILF3 and lncRNA ILF3-AS1 promotes melanoma proliferation, migration, and invasion. Cancer Manag Res 10: 6791-6802, 2018.

22. Hu XH, Dai J, Shang HL, Zhao ZX and Hao YD: SP1-mediated upregulation of IncRNA ILF3-AS1 functions a ceRNA for miR-212 to contribute to osteosarcoma progression via modulation of SOX5. Biochem Biophys Res Commun 511: 510-517, 2019.

23. Zhou M, Hu L, Zhang Z, Wu N, Sun J and $\mathrm{Su} J$ : Recurrence-associated long non-coding RNA signature for determining the risk of recurrence in patients with colon cancer. Mol Ther Nucleic Acids 12: 518-529, 2018.

24. Ye G, Guo L, Xing Y, Sun W and Yuan M: Identification of prognostic biomarkers of prostate cancer with long non-coding RNA-mediated competitive endogenous RNA network. Exp Ther Med 17: 3035-3040, 2019.

25. Wu W, Sui J, Liu T, Yang S, Xu S, Zhang M, Huang S, Yin L, $\mathrm{Pu} \mathrm{Y}$ and Liang G: Integrated analysis of two-lncRNA signature as a potential prognostic biomarker in cervical cancer: A study based on public database. PeerJ 7: e6761, 2019.

26. Mao X, Qin X, Li L, Zhou J, Zhou M, Li X, Xu Y, Yuan L, Liu QN and Xing H: A 15-long non-coding RNA signature to improve prognosis prediction of cervical squamous cell carcinoma. Gynecol Oncol 149: 181-187, 2018.

27. Tsikouras P, Zervoudis S, Manav B, Tomara E, Iatrakis G, Romanidis C, Bothou A and Galazios G: Cervical cancer: Screening, diagnosis and staging. J BUON 21: 320-325, 2016.

28. Li JH, Liu S, Zhou H, Qu LH and Yang JH: starBase v2.0: Decoding miRNA-ceRNA, miRNA-ncRNA and protein-RNA interaction networks from large-scale CLIP-Seq data. Nucleic Acids Res 42 (Database Issue): D92-D97, 2014

29. Agarwal V, Bell GW, Nam JW and Bartel DP: Predicting effective microRNA target sites in mammalian mRNAs. Elife 4: e05005, 2015.

30. Livak KJ and Schmittgen TD: Analysis of relative gene expression data using real-time quantitative PCR and the 2(-Delta Delta C(T)) method. Methods 25: 402-408, 2001.

31. Qu BL, Yu W, Huang YR, Cai BN, Du LH and Liu F: 6-OH-BDE-47 promotes human lung cancer cells epithelial mesenchymal transition via the AKT/Snail signal pathway. Environ Toxicol Pharmacol 39: 271-279, 2015. 
32. Wong SHM, Fang CM, Chuah LH, Leong CO and Ngai SC: E-cadherin: Its dysregulation in carcinogenesis and clinical implications. Crit Rev Oncol Hematol 121: 11-22, 2018.

33. van Roy F: Beyond E-cadherin: Roles of other cadherin superfamily members in cancer. Nat Rev Cancer 14: 121-134, 2014.

34. Angst BD, Marcozzi C and Magee AI: The cadherin superfamily: Diversity in form and function. J Cell Sci 114: 629-641, 2001

35. Osorio LA, Farfán NM, Castellón EA and Contreras HR: SNAIL transcription factor increases the motility and invasive capacity of prostate cancer cells. Mol Med Rep 13: 778-786, 2016.

36. Lamouille S, Xu J and Derynck R: Molecular mechanisms of epithelial-mesenchymal transition. Nat Rev Mol Cell Biol 15: 178-196, 2014.

37. Diepenbruck M and Christofori G: Epithelial-mesenchymal transition (EMT) and metastasis: Yes, no, maybe? Curr Opin Cell Biol 43: 7-13, 2016.

38. Cheng N, Wu J, Yin M, Xu J, Wang Y, Chen X, Nie Z and Yin J: LncRNA CASC11 promotes cancer cell proliferation in hepatocellular carcinoma by inhibiting miRNA-188-5p. Biosci Rep 39: BSR20190251, 2019

39. Slaby O, Laga R and Sedlacek O: Therapeutic targeting of non-coding RNAs in cancer. Biochem J 474: 4219-4251, 2017.

40. Ren L, Chen H, Song J, Chen X, Lin C, Zhang X, Hou N, Pan J, Zhou Z, Wang L, et al: MiR-454-3p-mediated Wnt/ $\beta$-catenin signaling antagonists suppression promotes breast cancer metastasis. Theranostics 9: 449-465, 2019.

41. Song Y, Guo Q, Gao S and Hua K: miR-454-3p promotes proliferation and induces apoptosis in human cervical cancer cells by targeting TRIM3. Biochem Biophys Res Commun 516: 872-879, 2019.

42. Wang S, Zhang G, Zheng W, Xue Q, Wei D, Zheng Y and Yuan J: MiR-454-3p and miR-374b-5p suppress migration and invasion of bladder cancer cells through targetting ZEB2. Biosci Rep 38 : BSR20181436, 2018.
43. Shao N, Xue L, Wang R, Luo K, Zhi F and Lan Q: miR-454-3p is an exosomal biomarker and functions as a tumor suppressor in glioma. Mol Cancer Ther 18: 459-469, 2019.

44. Li W, Feng Y, Ma Z and Lu L: Expression of miR-454-3p and its effect on proliferation, invasion and metastasis of colon cancer. Nan Fang Yi Ke Da Xue Xue Bao 38: 1421-1426, 2018 (In Chinese).

45. Malaney P, Uversky VN and Davé V: PTEN proteoforms in biology and disease. Cell Mol Life Sci 74: 2783-2794, 2017.

46. Chen CY, Chen J, He L and Stiles BL: PTEN: Tumor suppressor and metabolic regulator. Front Endocrinol (Lausanne) 9: 338, 2018.

47. Ortega-Molina A and Serrano M: PTEN in cancer, metabolism, and aging. Trends Endocrinol Metab 24: 184-189, 2013.

48. Nitulescu GM, Van De Venter M, Nitulescu G, Ungurianu A, Juzenas P, Peng Q, Olaru OT, Grădinaru D, Tsatsakis A, Tsoukalas D, et al: The Akt pathway in oncology therapy and beyond (Review). Int J Oncol 53: 2319-2331, 2018.

49. Milella M, Falcone I, Conciatori F, Cesta Incani U, Del Curatolo A, Inzerilli N, Nuzzo CM, Vaccaro V, Vari S, Cognetti F and Ciuffreda L: PTEN: Multiple functions in human malignant tumors. Front Oncol 5: 24, 2015.

50. Ye Z, Li Q, Guo Q, Xiong Y, Guo D, Yang H and Shu Y: Ketamine induces hippocampal apoptosis through a mechanism associated with the caspase-1 dependent pyroptosis. Neuropharmacology 128: 63-75, 2018. 